\title{
HIGH SIDE VOLTAGE CONTROLLER TO IMPROVE PERFORMANCE AND VOLTAGE STABILITY OF A POWER SYSTEM
}

\author{
H. A. Khattab \\ A. F. Nasef \\ G. A. Morsy \\ Department of Electrical Engineering Faculty of Eng. Menoufia University, Egypt.
}

\begin{abstract}
:-
This paper describes a high side voltage controller (HSVC) design, implementation and performance study for a synchronous generating unit connected to an infinite bus power system via a transformer and a double-circuit transmission line. In addition to enhance the system performance, the HSVC can improve power system voltage stability by adding supplemental control to conventional generator excitation system. The simulation results using detailed nonlinear model for the system with: a conventional automatic voltage regulator (AVR), power system stabilizer (PSS), and applying HSVC, are obtained. These results illustrate the superiority of HSVC to enhance the system performance as well as its voltage stability when subjected to different disturbances.

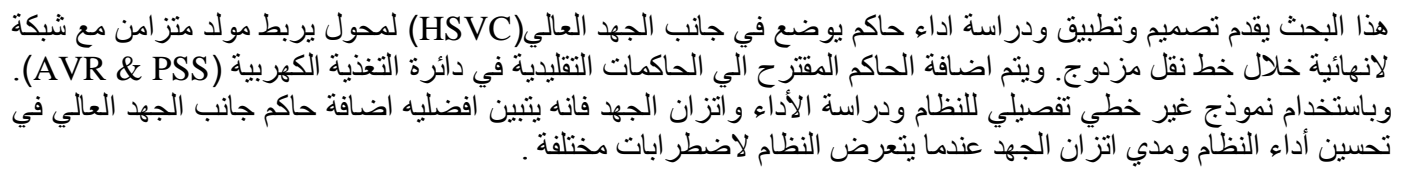

Key-words: - Synchronous generator, HSVC, AVR, PSS, Voltage stability, Voltage Droop Rate

\begin{abstract}
1 Introduction
The electric power system is complex in nature. This renders the system to operate with generator poor performance and with a lower margin of stability when subjected to a disturbance [1].

The austerity of the sudden disturbance affects directly the power system generator variables such as: rotor speed which directly affects the system frequency and rotor angle which directly affects the transferred power. Following to large disturbance, the system behavior may loss synchronism, cause falling out generating units and produce voltage collapse.

To improve the power system performance and to extend its operational margin of stability during the steady-state and transient conditions the power system is equipped with different control systems [2].

The excitation control is the common control strategies. The excitation control is performed firstly by using automatic voltage regulator (AVR), which is a high gain placed in excitation system employing a feed-back control signal from the terminal voltage to maintain the terminal voltage fixed within tolerance of $₫ 0.5 \%$ from a reference value [2]. The power system stabilizer (PSS) is introduced to provide the system with positive damping during normal and abnormal conditions [3, 4]. Power system angle and voltage stability is improved by
\end{abstract}

tight regulation of transmission voltage. For transient (short-term) angle or voltage stability, high-speed control is required [5].

HSVC has been developed with no requirement for any direct feedback signal from the high voltage side of a step-up transformer. This can be easily realized by using only the signals provided for the conventional automatic voltage regulator (AVR), i.e., the generator voltage from the voltage transformer VT, and the generator current from the current transformer CT [6]. The sending end (source) transmission voltages can be kept high at all power plants by the HSVC proposed here. The receiving end (load) voltage profiles could be maintained by switched capacitor banks and powerelectronic-based Var sources where necessary. The HSVC improve system performance, voltage stability and transmit much power at the same voltage.

This paper describes the design and implementation of a HSVC which controls the high side voltage of the generator step-up transformer. The simulation results for the system when applying HSVC in comparison with a conventional automatic voltage regulator (AVR) and power system stabilizer (PSS) are obtained. These results illustrate that, using HSVC the system performance and its voltage stability are enhanced effectively when subjected to different disturbances. 


\section{System Descriptions}

In this study, the power system model defined by a conventional synchronous generator connected to a large power system via a transformer and a doublecircuit transmission line, is shown in Fig. (1). A description of the individual elements of the system is given subsequently and the parameters are shown in the Appendix.

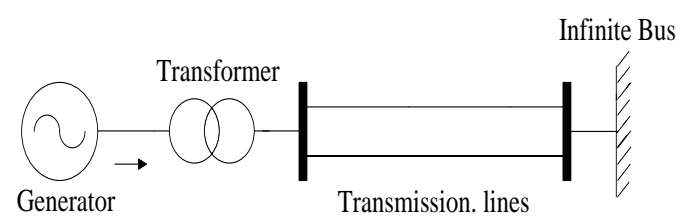

Fig. 1. Schematic diagram of a turbogenerator system

\subsection{Generator}

Based on park's d-q axes, a seventh-order nonlinear mathematical model representation is established. The differential equations are arranged as a set of first order equations as following [7]:

I-Mechanical equations:

$p \tilde{0}=\omega$

$p w=\frac{w_{m}}{2 H}\left(T_{\mathrm{m}}-\mathrm{T}_{\mathrm{e}}\right)$

$\mathbb{T}_{\mathrm{e}}=\Psi_{\mathrm{d}} \mathrm{i}_{\mathrm{q}}-\Psi_{\mathrm{q}} \mathrm{i}_{\mathrm{d}}$

II-Field circuit representation:

$p \Psi_{\mathrm{f}}=\omega_{0}\left(E_{\mathrm{fd}} \frac{\mathbb{E}_{\mathrm{f}}}{\mathbb{X}_{\mathrm{fd}}}-\mathbb{1}_{\mathrm{f}} R_{\mathrm{f}}\right)$

III-Stator representation:

$$
\begin{aligned}
& p \Psi_{\mathbb{d}}=\omega_{0}\left(V_{d}+i_{d} R_{\mathrm{a}}+\Psi_{q}\right)+\omega \Psi_{q} \\
& p \Psi_{q}=\omega_{0}\left(V_{q}+i_{q} R_{a}-\Psi_{d}\right)-\omega \Psi_{d}
\end{aligned}
$$

IV-Damper windings representation:

$$
\begin{aligned}
& p \Psi_{D}=-\omega_{0}{ }^{\frac{1}{1}} R_{D} \\
& p \Psi_{Q}=-\omega_{0}{ }_{Q} R_{Q}
\end{aligned}
$$

The currents are obtained as a function of flux linkages.

V-Terminal voltage:

$$
V_{t}=\sqrt{V_{Q}^{2}+V_{q}^{2}}
$$

VI-Terminal power:

$$
P_{t}=V_{d} \mathbb{1}_{d}+V_{q} \mathbb{1}_{q}
$$

\subsection{Transformer and transmission line}

Lumped series inductance and resistance are used to represent the transformer and the transmission line connecting the generator to the grid. In a similar manner to that described for the generator, the transmission system components are solved in the generator d-q axes as follows:

$$
\begin{aligned}
& V_{d}=V_{b} \sin \delta+r_{d} i_{d}-X_{e} i_{q} \\
& V_{q}=V_{b} \cos \delta+r_{G} i_{q}-X_{e} i_{d}
\end{aligned}
$$

\subsection{Excitation system}

Various types of exciters have been used with different ceiling voltages. However, we use thyristor exciter, which provide very fast control, facilities rapid and continuous control of the exciter-field current to keep the terminal voltage constant because of its small time constant [8]. A high gain automatic voltage regulator (AVR) is used to control generator terminal voltage. The block diagram of the excitation system is shown in Fig. (2) [7]. Analysis of modern voltage regulators shows that under heavy load conditions the continuously acting of excitation systems introduces negative damping. To offset this effect and to improve the system damping in general, a power system stabilizer (PSS) is added with each excitation system to produce positive damping torques in phase with the speed $[9,10]$. The transfer function of the PSS is shown by broken line in Fig. (2). PSS is a lead lag compensator with gain $\mathrm{G}_{\mathrm{s}}$ and two time constants $\mathrm{T}_{1}$ and $\mathrm{T}_{2}$.

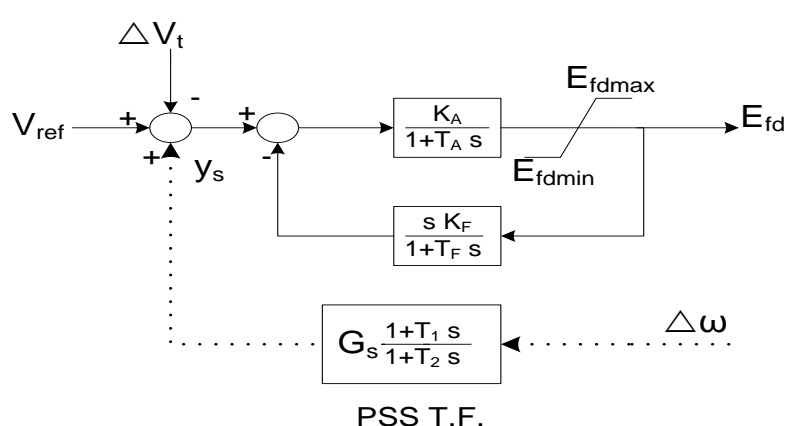

Fig. 2. Excitation system 


\subsection{Turbine and Governor System}

The turbine and governor system is shown in Fig. (3). It represents a simple steam turbine model with a single gain, $\mathrm{K}_{t}$, and time-constant, $\mathrm{T}_{\mathrm{t}}[11]$. The speed governor is also considered with single gain $\mathrm{K}_{\mathrm{g}}$ and single time-constant $\mathrm{T}_{\mathrm{g}}$.

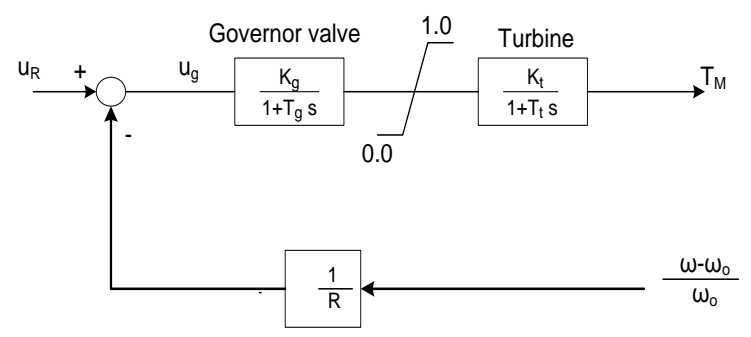

Fig. 3. Representation of turbine and governor system

\section{High Side Voltage Controller}

The configuration of the HSVC is shown in Fig. (4).

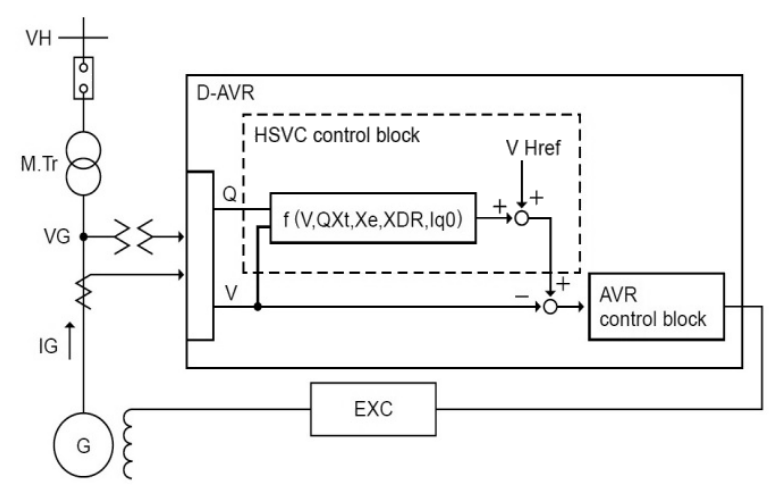

Fig. (4). Construction of HSVC control system

From Fig. (4), the HSVC compensate the drop in the transformer which takes signals from terminal voltage and terminal current. So, the new generator reference Vgref will be the addition of the output of HSVC and VHref which compare with terminal voltage [6].

When the Vg is controlled by the advanced HSVC, the $\mathrm{Vg}$ may be generally maintained higher than its rated voltage in order to keep the $\mathrm{VH}$ to a constant value. On the other hand, the continuous allowable $\mathrm{Vg}$ is generally up to $5 \%$ of the rated voltage. If the $\mathrm{Vg}$ is near this maximum voltage in a steady state condition, the improving effect of the voltage stability by the advanced HSVC is reduced by this limitation. However, the voltage droop rate changes according to the variation of the voltage ratio and the reactance of the step-up transformer $\left(\mathrm{X}_{\mathrm{t}}\right)$.

The relationship between the low side voltage $\mathrm{Vg}$ and the high side voltage $\mathrm{VH}$ of the step-up transformer is represented as:

$$
\overline{\mathrm{Wg}}=\mathrm{WH}+\mathrm{Nt} * \mathrm{Ig}-
$$

where $\mathrm{Ig}=\mathrm{Pg} / \mathrm{Vg}-1 \mathrm{Qg} / \mathrm{Vg}$, with the resistance of the step-up transformer is small and neglected. Assuming nominal turns ratio the high side voltage can be controlled to the target value VHref by controlling the generator voltage according to Eqn. (13), that is ( voltage drop being completely compensated via $X_{t}$ ). However, generator current and reactive power will be imbalanced with multiple generators controlling the same voltage.

Also, the high side voltage is controlled according to Eqn. (14), which contains a voltage droop characteristics. These characteristics can be expressed as shown in Fig. (5).

$\mathrm{VH}=\mathrm{VHref}-\mathrm{XDR} *$ iq

Where, iq $=\mathrm{Qg} / \mathrm{Vg}$.

Putting Eqn. (14) and Fig. (5) into words, for a target of VHref, VH can be controlled with a slope reactance of XDR.

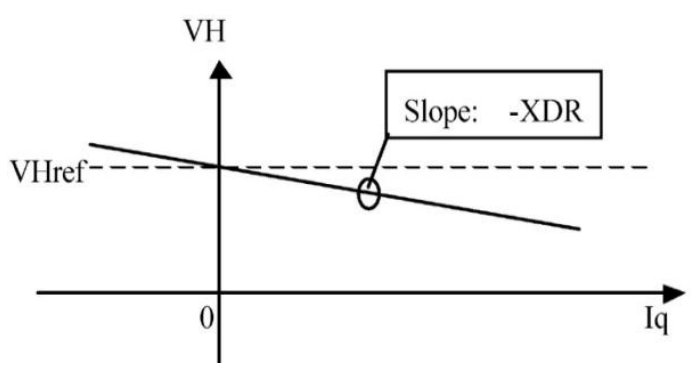

The active power Pg and the reactive power Qg of the generator shown in Fig. (1) can be respectively represented by Eqns. (15) and (16) using the low side voltage $\mathrm{Vg}$, the high side voltage $\mathrm{VH}$ and the step-up transformer reactance $\mathrm{Nt}$.

$\mathrm{Pg}=\frac{\mathrm{Wg} W \mathrm{H}}{\mathrm{Xt}} \sin \delta$

$\mathrm{Qg}=\frac{\mathrm{Wg}^{2}-\mathrm{Wg}_{\mathrm{g}} \mathrm{WH} \cos 8}{\mathrm{Xt}}$

Therefore, the relation between the low side voltage Vg and the high side voltage $\mathrm{VH}$ can be derived from Eqn. (16) as: 


$$
\mathrm{VH}=\frac{\mathrm{Wg} \mathrm{g}^{2}-\mathrm{XtQg}}{\mathrm{Tg} \cos 8}
$$

Neglecting the effect of the angle, Eqn. (17) can be approximated as shown in Eqn. (18).

$$
\mathrm{WH}=\mathrm{Vg}-\frac{\mathrm{XtQg}}{\mathbb{V}_{\mathrm{g}}}
$$

The reference terminal voltage Vgref which wanted to be controlled can be calculated corresponding to the target high side voltage VHref for the original HSVC as:

Wgref $=$ WHref $+(\mathrm{Xt}-\mathrm{XDR}) i \mathrm{q}$

where ${ }^{\mathrm{i}} \mathrm{q}=\mathrm{Qg} / \mathrm{Wg}$, and $\mathrm{XDR}$ is the droop.

The primary improvement in the HSVC is the inclusion of the "real" component of Ig. (Note that the resistance of the step-up transformer is still omitted) Thus, the vector diagram that represents the relation of $\mathrm{Vg}$ and $\mathrm{VH}$ with $\mathrm{Vg}$ being the basis of angle is shown in Fig. (6).

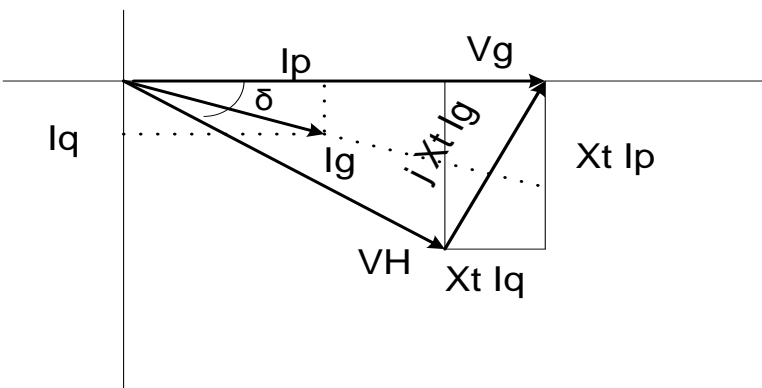

Fig. (6).Vector diagram of $\mathrm{V} g$ and $\mathrm{VH}$.

From this figure, the relation of $\mathrm{WH}$ and $\mathrm{Wg}$ can be represented as:

$$
\begin{aligned}
& V H=\sqrt{(V g-X t i q)^{2}+(X t i p)^{2}} \\
& \text { where } i p=P g / V g \text { and } \quad \text { iq }=Q_{g} / V g, \\
& V g=V g \\
& V H=V H(\cos \delta+j \sin \delta) .
\end{aligned}
$$

\section{Simulation Results}

To achieve a higher level of accuracy in the predicted results and draw a general conclusion from the results, detailed representation were made for all system components. The transient performance of the simulated non-linear system with the conventional excitation control (AVR and PSS) and when the new controller (HSVC) to the system added were examined for a symmetrical three-phase short circuit (120 ms duration) at the transformer high voltage side.

Initially, the simulation results are obtained in comparative form using Voltage Droop Rate (XDR) with different values as shown in Figs.(7) and (8) taking the effect of AVR with HSVC and the effect of AVR and PSS with HSVC.

These results illustrate that the best performance of the system obtained with the droop $0.04(4 \%)$ as it provide good damping to electromechanical mode of oscillations and all system variables quickly return to their initial values.

Representing the HSVC Regulator according to Eqn. (19) and taking the voltage droop rate $\mathrm{XDR}=4 \%$. The simulation results are obtained in comparative form for the power system when equipped with conventional excitation controls (AVR and PSS) only and when the new controller (HSVC) added. Figs. (9) through (10), shows the results when the system subjected to a symmetrical three-phase short circuit for $120 \mathrm{~ms}$ duration.

These results illustrate generally that using the HSVC with conventional excitation controls enhance the system performance in terms of damping increase and all system variables were quickly returned to their nominal values.

\section{Improvement of Voltage Stability}

Voltage control and stability problems are not new to the electric utility industry but are now receiving special attention in many systems. Voltage problems are now a source of concern in highly developed networks as a result of heavier loadings.

Voltage stability is concerned with the ability of the power system to maintain acceptable voltages at all buses in the system under normal conditions and after being subjected to disturbances.

To study the voltage stability phenomena the V-P characteristics is drawn as shown in Fig. (11).

\section{Conclusions}

This paper presented the design and implementation of HSVC to enhance the power system performance as well as its voltage stability. The proposed controller was validated via detailed model nonlinear simulation. Simulation results for the system were obtained when equipped with the proposed HSVC in comparison with others obtained for the system with conventional excitation control.

The simulation results demonstrate clearly that HSVC can improve both system performance (in 
terms of damping increase and fast return of all system variables to their initial values) and voltage stability margin.

\section{List of Symbols}

$p$ The derivative operator' $\mathrm{d} / \mathrm{dt}$ '

$\omega_{0}$ Angular frequency of the infinite bus

$\omega$ Angular speed deviation of the rotor

$\Psi_{\mathbb{d} x} \Psi_{q}$ Stator flux linkages in d- and q- axis circuits

$V_{\mathbb{d}} V_{G}$ Stator terminal voltage in $\mathrm{d}$ - and q-axis circuits

$\mathbb{1}_{\mathrm{d}} \mathrm{I}_{\mathrm{q}}$ Stator currents in $\mathrm{d}$ - and $\mathrm{q}$ - axis circuits

$\mathbb{R}_{\text {a }}$ Stator resistance

$\mathbb{R}_{\mathrm{f}}, \mathrm{p}_{\mathrm{f}}$ Field circuit resistance and current

$X_{g} . x_{g}$ Combined reactance and resistance of transformer and transmission lines

5 Rotor angle

$\mathbb{T}_{\mathrm{m}}$ Input mechanical torque

$\mathbb{T}_{\circledast}$ Output electrical torque

$\mathrm{R}$ speed regulation due to governor action

\section{Appendix:}

1) MACHINE PARAMETERS (P.U):

$$
\begin{aligned}
& \mathrm{H}=3.25 \quad \mathrm{X}_{\mathbb{A}}=2.0 \\
& \mathrm{X}_{\text {ad }}=1.86 \quad \mathrm{X}_{\mathrm{q}}=1.91 \\
& \mathrm{X}_{\mathrm{aq}}=1.77 \quad \mathrm{X}_{\mathrm{KQ}}=1.96 \\
& \mathrm{X}_{f d}=1.97 \quad \mathrm{X}_{K D}=1.94 \\
& R_{K Q}=0.0084 \quad R_{K D}=0.0078 \\
& \mathrm{r}_{\Omega}=0.005 \quad \mathrm{~T}_{\mathbb{f}}=0.5 \\
& r_{f}=0.0015 \quad R=0.04 \text { P.U.HZ/MW }
\end{aligned}
$$

\section{2) TRANSMISSION SYSTEM:}

$$
\begin{array}{ll}
X_{T}=0.1 \text { P.U. } & R_{T}=0.038 \text { P.U. } \\
X_{\mathbb{L}}=0.35 \text { P.U. } & R_{\mathbb{L}}=0.025 \text { P.U. }
\end{array}
$$

\section{References:}

[1] G. K. Venayagamerthy and R. G. Harley, "A continually online trained neurocontroller for excitation and turbine control of a turbogenerator", IEEE Trans. On Energy Conv., Vol.16, No.3, Sept.2001, pp.261-269.

[2] G. A. Morsy, "Control of Multi-machine power systems", Ph.D. Thesis, Menoufia University, 1991.

[3] K. R. Padiyar, "Power System Dynamics: Stability and Control", John Wiley \& Sons (Asia) Pre Ltd., 1996.

[4] E. A. Mohamed et al, "Efficient Power System Stabilizer Configuration Based on Linear Optimal Control and ANN". MEPCON 2000, Ain Shams University, Egypt, March 28-30, 2000.

[5] C. W. Taylor, "Power System Voltage Stability". New York: McGraw-Hill, 1994.

[6] S. Noguchi, M. Shimomura and J. Paserba, "Improvement to an Advanced High Side Voltage Control", IEEE Trans. On POWER SYSTEMS, VOL. 21, NO. 2, MAY 2006, pp. 683-692.

[7] S. M. Osheba et al, "Comparison of transient performance of superconducting and conventional generators in a multimachine system", IEEE-Proc.135, pt. C, No.5, Sept. 1988, pp. 389-395.

[8] D. R. Fenwick and W. G. Wright, "Review in excitation systems and possible future development", Proc. IEEE, 1976. 123. pp. 413-420.

[9] A. H. El-Abiad, "Power system analysis and planning", Purdue University, West Lafayette, Indiana USA, 1983.

[10] S. M. Osheba and B. W. Hogg, "Multivariable controller for a turbo generator", IEEE PES Winter Meeting, Feb. 1980.

[11] IEEE Committee Report: "Dynamic models for steam and hydro turbines in power system studies", IEEE Trans., 1973, PAS-92, pp. 1904-1915. 

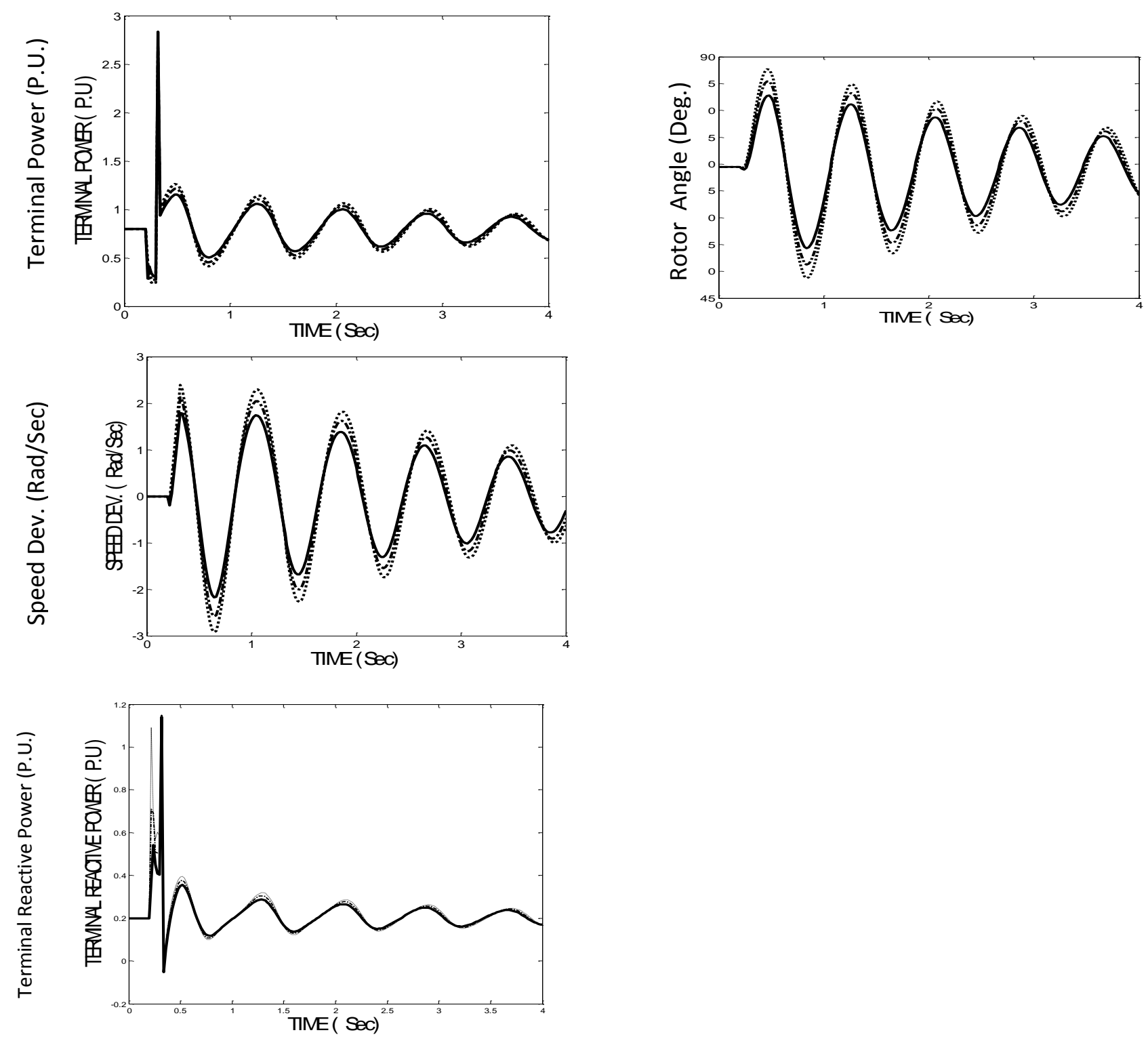
Fig.(7) System response to a 3-phase short circuit for $120 \mathrm{~ms}$ at lagging p.f. the system equipped with AVR and HSVC
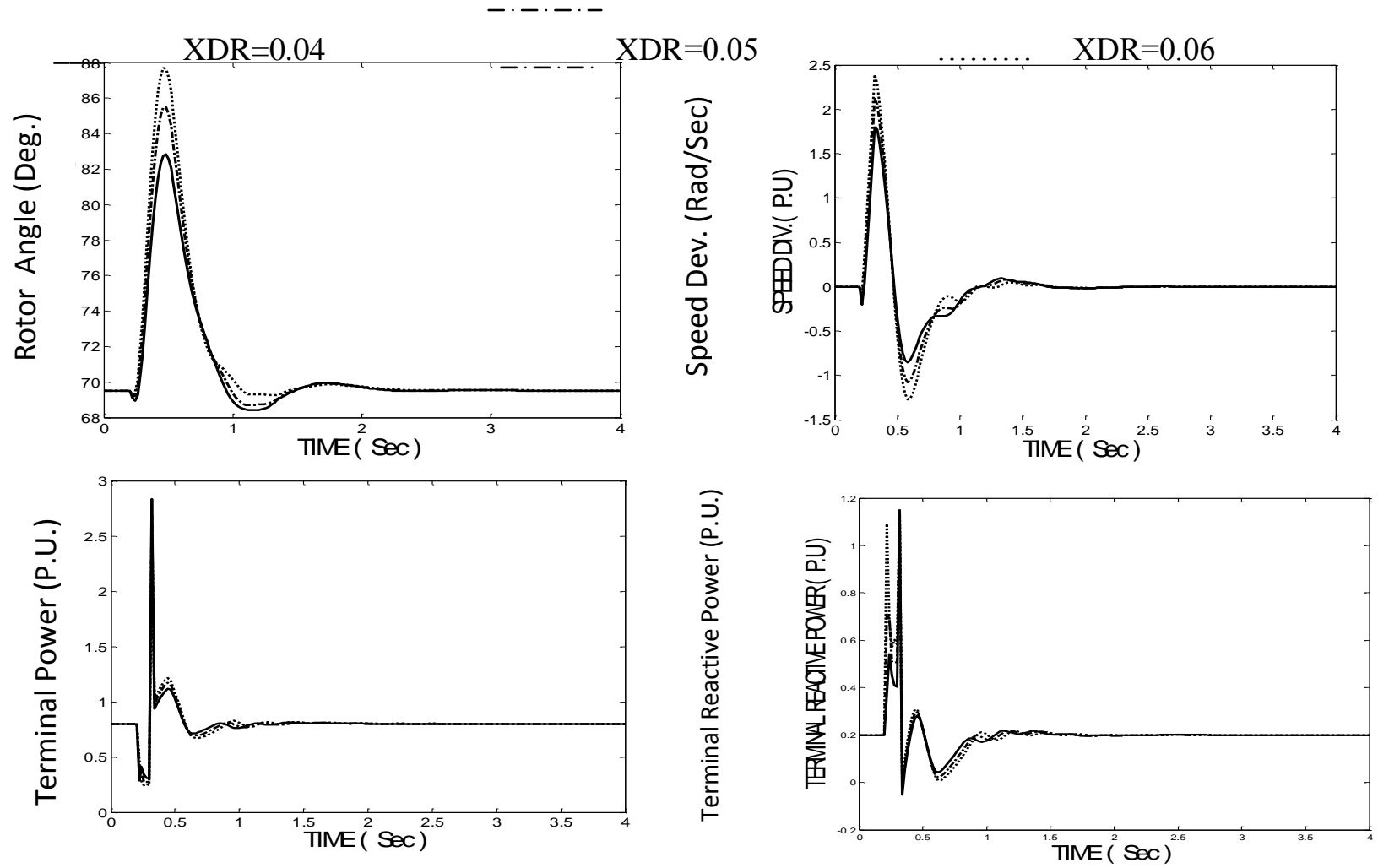

Fig.(8) System response to a 3-phase short circuit for $120 \mathrm{~ms}$ at lagging p.f. ( $\mathrm{Pg}=0.8, \mathrm{Qg}=0.2)$, the system equipped with AVR,PSS and HSVC
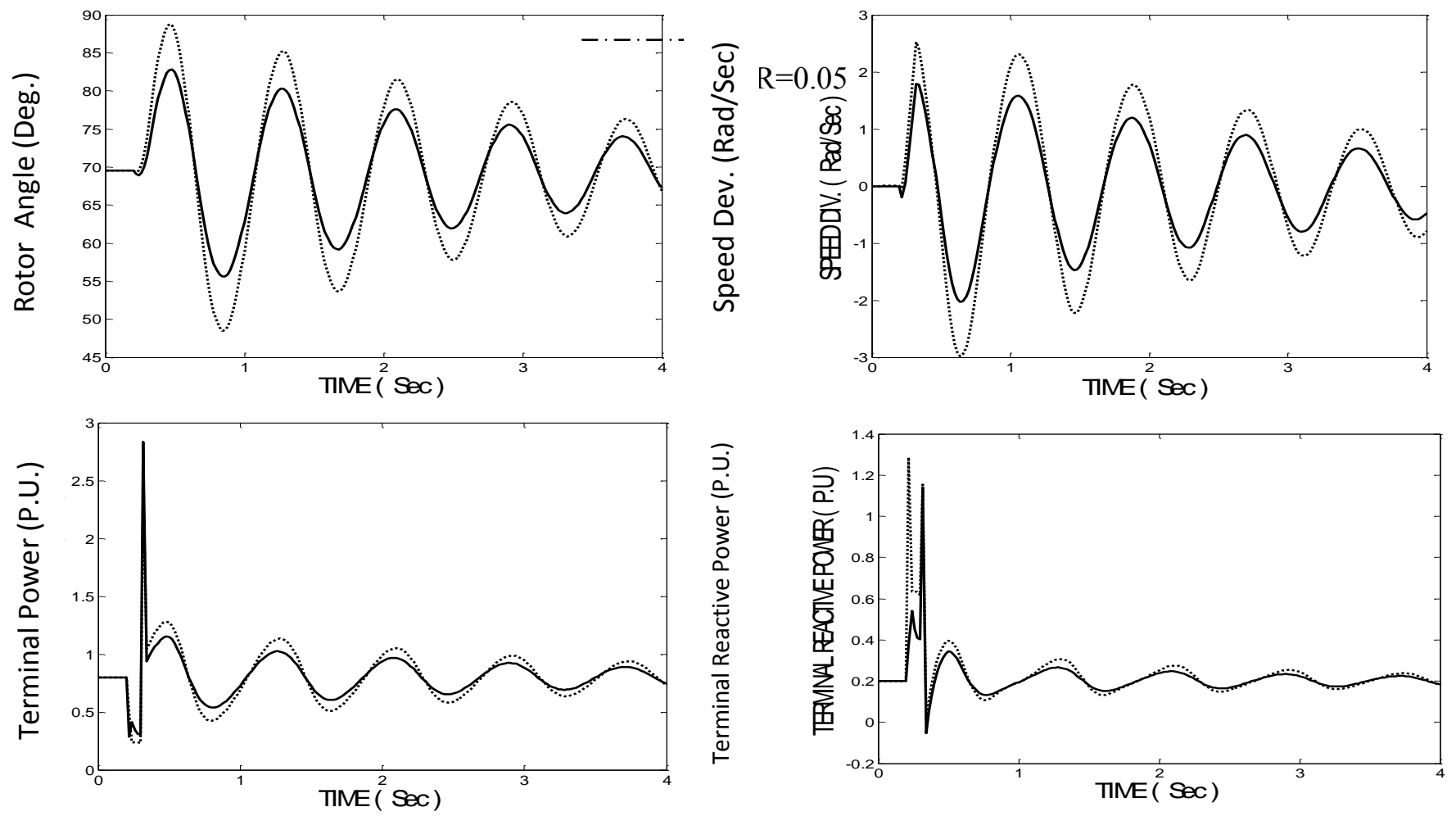
Fig. (9) System response to a 3-phase short circuit for $120 \mathrm{~ms}$ at lagging p.f. (pg=0.8, $\mathrm{Qg}=0.2$ )

HSVC $+\mathrm{AVR}$
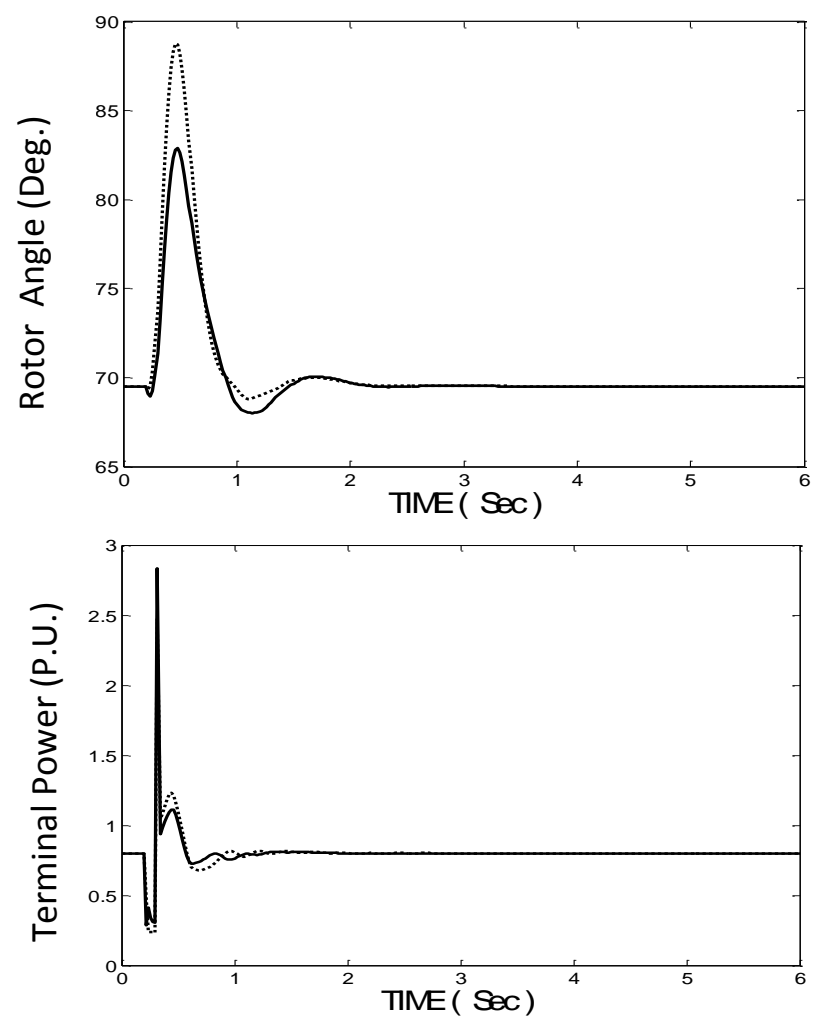

......... AVR
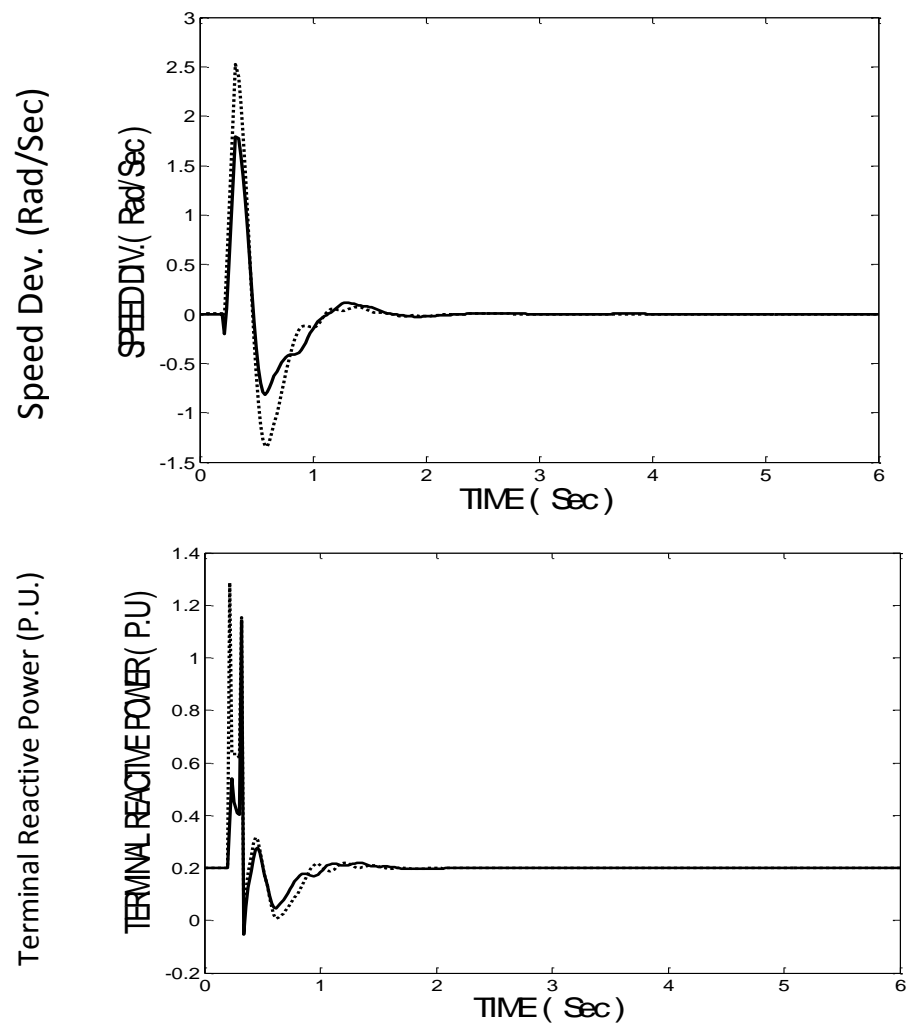

Fig. (10) System response to a 3-phase short circuit for $120 \mathrm{~ms}$ at lagging p.f. (pg=0.8, $\mathrm{Qg}=0.2$ ) $\mathrm{HSVC}+\mathrm{AVR}+\mathrm{PSS}$

AVR + PSS

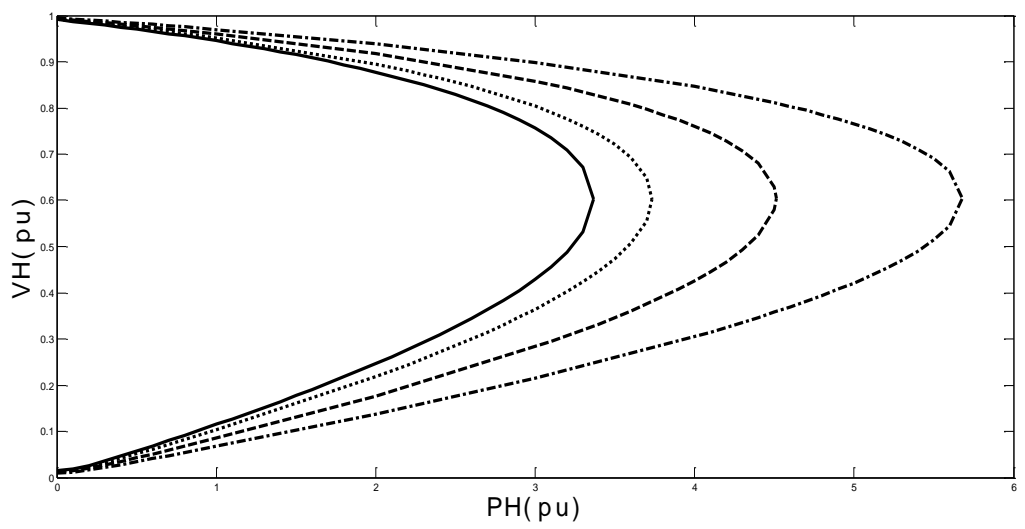

Fig. (11) The V-P CURVE at operating point $\mathrm{Pg}=0.8, \mathrm{Qg}=0.2$

BASIC CAS (AVR+PSS)

$\mathrm{AVR}+\mathrm{PSS}+\mathrm{HSVC}(\mathrm{XDR}=0.04)$
$\mathrm{AVR}+\mathrm{PSS}+\mathrm{HSVC}(\mathrm{XDR}=0.06)$

$\mathrm{AVR}+\mathrm{PSS}+\mathrm{HSVC}(\mathrm{XDR}=0.05)$ 